Dysphagia

\section{A woman with dysphagia and Raynaud's phenomenon}

\section{R Gaya, R Mactier}

\section{Authors' affiliations}

D R Gaya, R Mactier, Department of Medicine,

Glasgow Royal Infirmary, Castle Street,

Glasgow G4 OSF, UK

Correspondence to: Dr Gaya;

danielgaya@aol.com

Submitted 13 July 2001

Accepted 21 August 2001

Answers on $p 109$.

A

69 year old woman with no relevant past medical history was admitted with dysphagia. She reported difficulty swallowing both solids and liquids and that it had been gradually worsening over a 10 year period. She denied pain on swallowing and there was no history of regurgitation, heartburn, corrosive ingestion, or weight loss. There was a 25 year history of intermittent attacks of pallor, pain, and redness of the digits.

\section{QUESTIONS}

(1) Comment on the appearance of her tongue (fig 1), face (figs 3 and 4), and hands (fig 5).

(2) Comment on the appearance of her barium swallow (fig 2) and suggest a unifying diagnosis.

(3) Examination of her left elbow revealed a hard nodule over the extensor aspect. What does the radiograph (fig 6) show?

All photographs reproduced with patient's permission.

Postgrad Med J 2002;78: 102-103

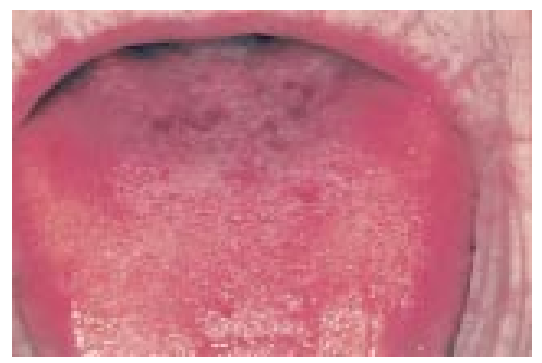

Figure 1

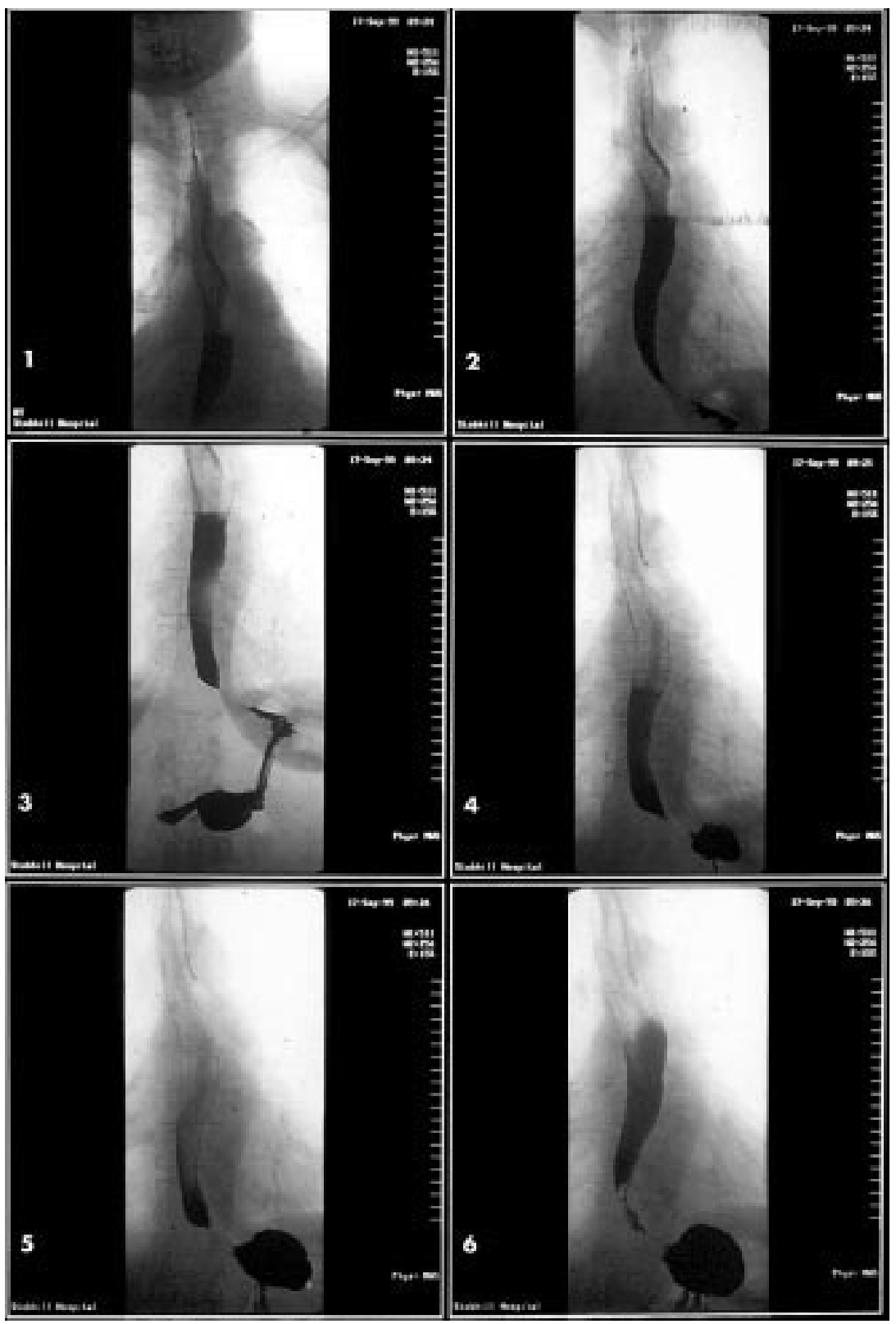

Figure 2 

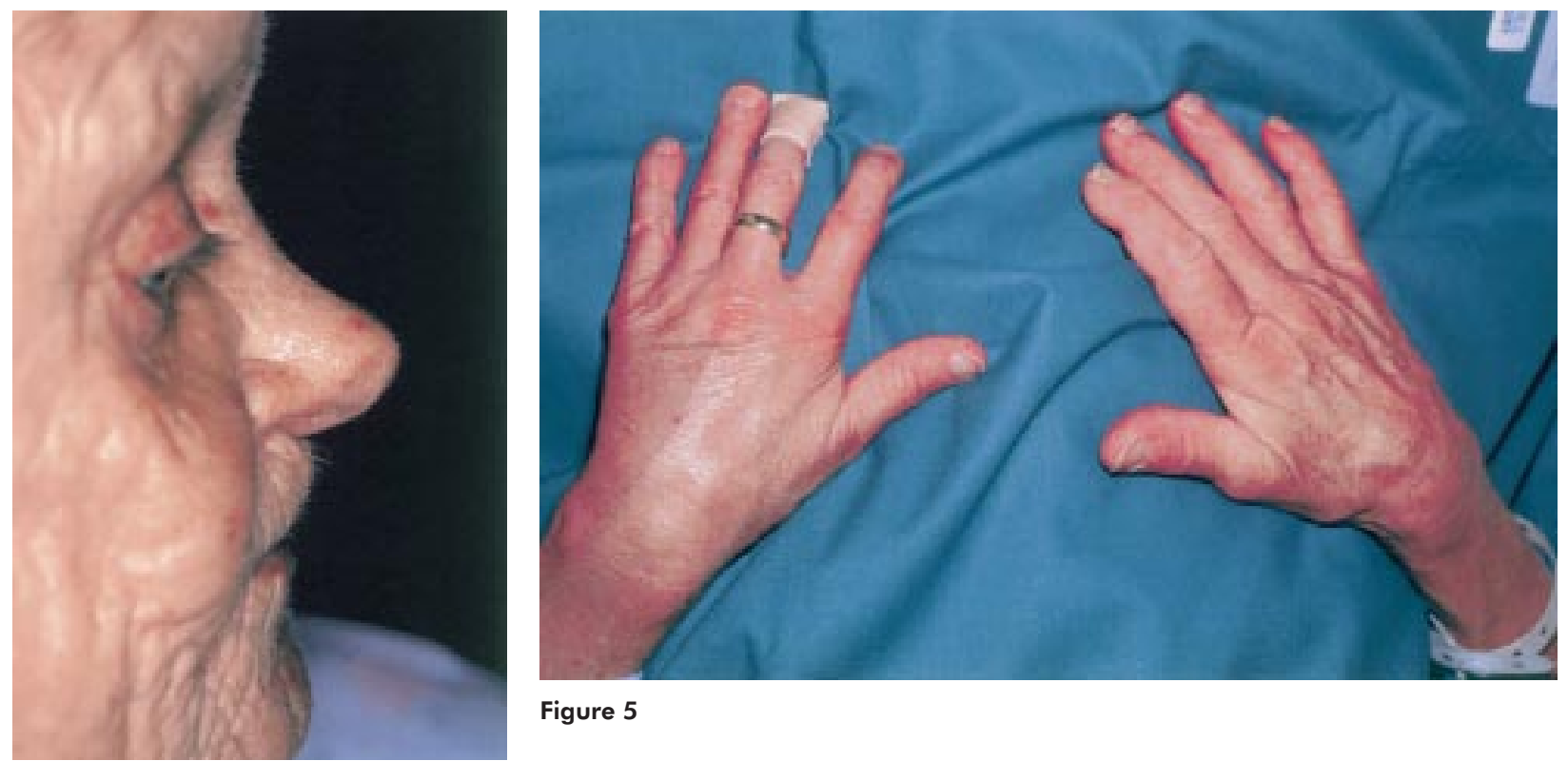

Figure 5

Figure 3

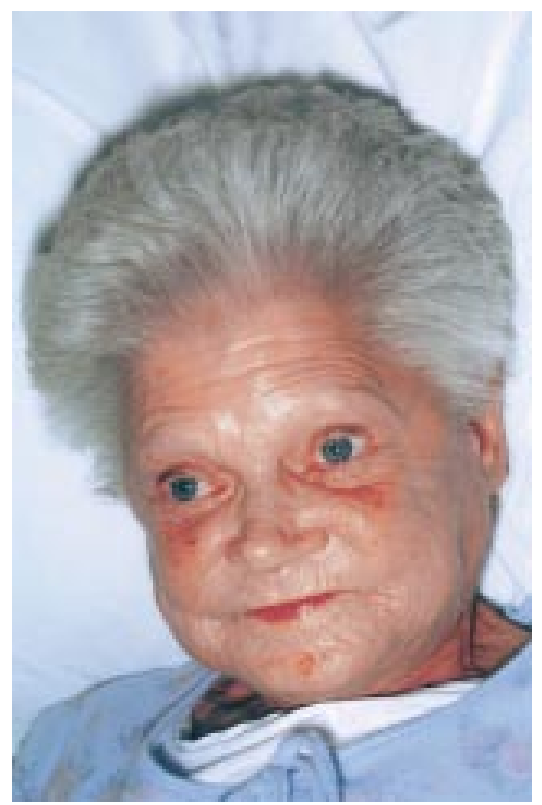

Figure 4

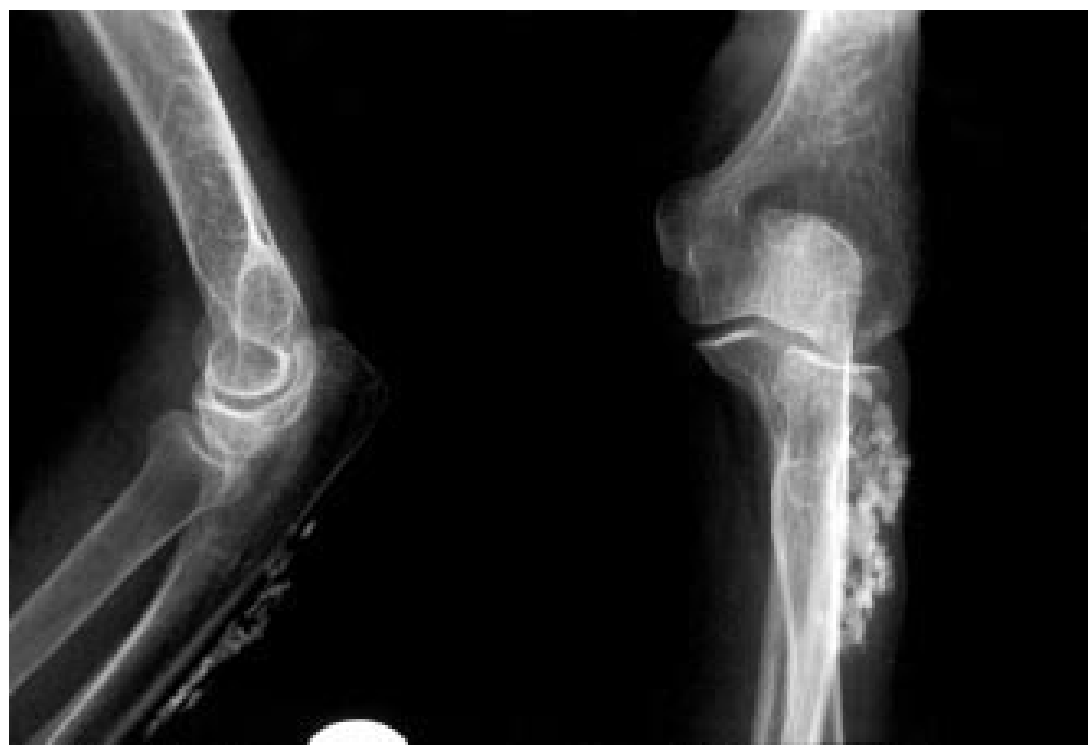

Figure 6

Chronic renal failure

\section{An unusual case of chronic renal failure}

\section{A L Manoi, A Dhaygude}

\section{Answers on p 110.}

A previously healthy 47 year old driver presented with a six week history of headache, vomiting, tiredness, and unsteadiness of feet.
Examination revealed marked pallor, the pulse was regular at 97 beats $/ \mathrm{min}$, blood pressure was raised at $180 / 116$ $\mathrm{mm} \mathrm{Hg}$, and the minimental test score was 6/10. The cranial nerves were normal, as was his power in all four limbs. Bulk and tone were normal, but all the deep tendon reflexes were brisk. Sensation were intact. The finger, nose, and heel shin test were normal. Gait was wide based. Cardiovascular examination revealed a short ejection systolic murmur at the mitral area. The rest of the clinical examination was unremarkable.

Investigations on admission revealed a normochromic, normocytic anaemia with a haemoglobin of $86 \mathrm{~g} / \mathrm{l}$, and a normal white cell and platelet count. His erythrocyte sedimentation rate was raised at 38 $\mathrm{mm}$ in the first hour. The patient had a normal sodium concentration of 138 


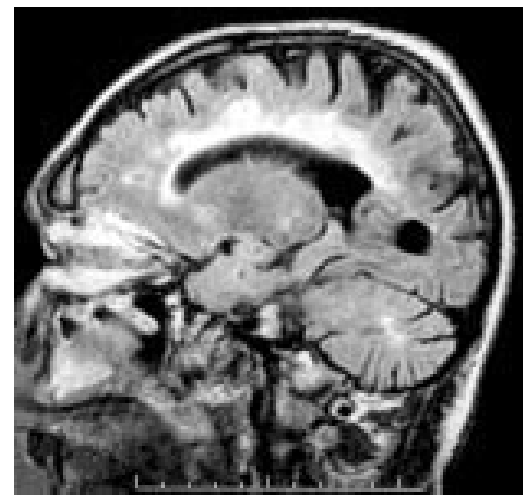

Figure 1 Magnetic resonance image of the brain.

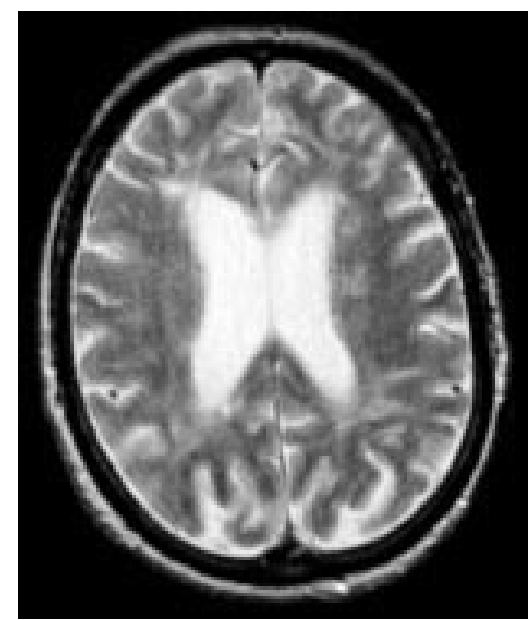

Figure 2 Computed tomogram of the head showing widespread ischaemic changes.

$\mathrm{mmol} / \mathrm{l}$ and serum potassium of 4.6 $\mathrm{mmol} / \mathrm{l}$. His urea and creatinine concentrations were raised at $26 \mathrm{mmol} / \mathrm{l}$ (reference range 2.5-8.0) and $609 \mathrm{\mu mol} / \mathrm{l}$ (60-100) respectively. His 24 hour urine collection showed proteinuria of $1.7 \mathrm{~g} /$ day. His serum B12, serum folate, and thyroid stimulating hormone were normal.

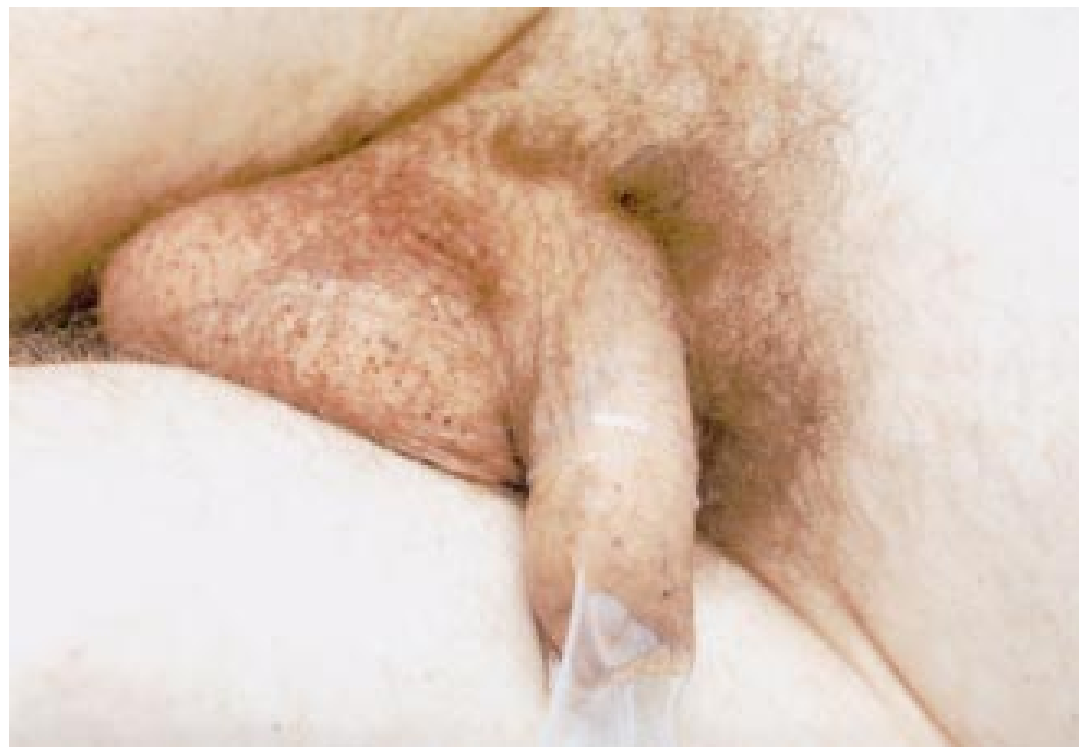

Figure 3 Bathing trunk area showing rash (reproduced with patient's permission).

Antineutrophil cytoplasmic antibody and antinuclear factor were negative and serum C3 and C4 were normal. Protein electrophoresis was normal. His electrocardiogram showed left ventricular hypertrophy with strain pattern and his chest radiograph was normal. Ultrasound of the kidneys revealed bilateral small kidneys with a biparietal diameter of $9 \mathrm{~cm}$. A computed tomogram of the head showed wide spread ischaemic changes notably in the periventricular white matter and basal ganglia. Magnetic resonance imaging (MRI) and computed tomography of the head were done (figs 1 and 2). The patient was transferred to a tertiary centre where a renal biopsy was performed which revealed that most of the glomeruli was sclerosed with tubular atrophy, interstitial fibrosis, and severe blood vessel hypertrophy. During his stay in the hospital a rash was noted on the bathing trunk area (fig 3).

\section{QUESTIONS}

(1) What does the MRI scan show?

(2) What is shown in fig 3 ?

(3) What is the diagnosis?

(4) What do you expect to see in the electron microscopic examination of the kidney?

(5) What investigation will you do to confirm the diagnosis?

Postgrad Med J 2002;0: 103-104

\section{Authors' affiliations}

A L Manoj, A Dhaygude, Department of Medicine, Peterborough District Hospital, Peterborough PE3 6DA, UK

Correspondence to: Dr Manoj; manojal@hotmail.com

Submitted 16 February 2001

Accepted 15 May 2001

productive of purulent sputum, and cough on attempted swallowing. She had a past history of resection of a

\section{A case of cough and dysphagia}

\section{M Smyth, C C Evans}

Answers on $p 111$.

A 70 year old women was referred to the accident and emergency department by her general practitioner with a three month history weight loss of two stone $(13 \mathrm{~kg})$ and progressive dysphagia for solids. This had worsened to the extent that over the week before presentation, she had difficulty swallowing soft food and fluids. She also reported recent onset of cough

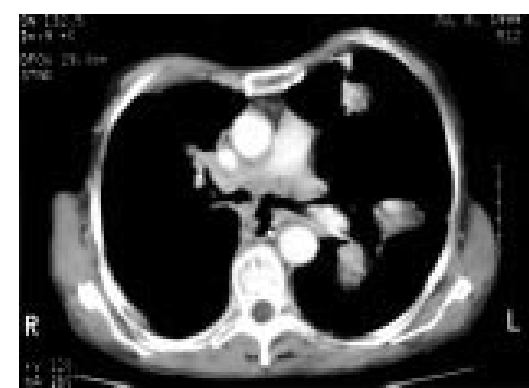

Figure 1 Computed tomogram. 
Dukes's stage B colon carcinoma eight years earlier. She was a smoker of 15 cigarettes a day, and drank little alcohol. She took no regular medication.

On examination she appeared thin and dehydrated. Cardiovascular and abdominal examination was unremarkable. Chest auscultation revealed crackles at both lung bases.

Blood tests revealed a urea of 13.7 $\mathrm{mmol} / \mathrm{l}$ (normal 2.5-7.0) and a neutrophilia of $9.1 \times 10^{9} / 1$ (normal 2.0-7.5). Chest radiography showed patchy shadowing throughout both lung fields.

The patient was rehydrated intravenously and started on broad spectrum antibiotics. A nasogastric tube was passed. Upper gastrointestinal endoscopy revealed an obstructing mass at the mid-oesophagus. A bronchoscopic examination and computed tomography of the thorax were performed.

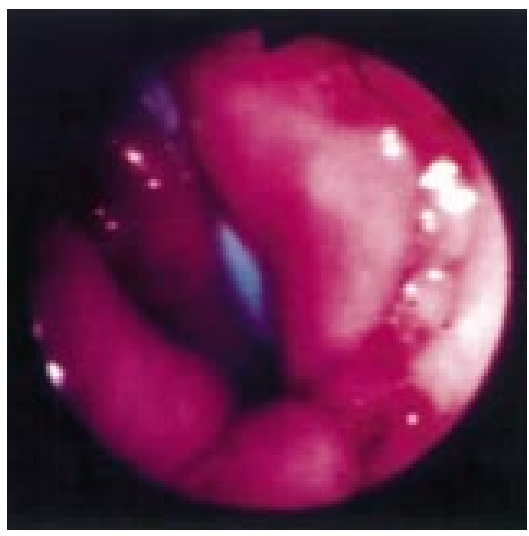

Figure 2 Right main bronchus at bronchoscopy.

\section{QUESTIONS}

(1) What abnormalities are seen on the computed tomogram (fig 1) and on

views of the right main bronchus at bronchoscopy (fig 2)?

(2) What is the most likely cause of these appearances?

(3) What other conditions may cause similar appearances?

(4) What treatment options are available?

Postgrad Med J 2002;78:104-105

\section{Authors' affiliations}

C M Smyth, C C Evans, Royal Liverpool University Hospital, Prescot Street, Liverpool L7 8XB, UK

\section{Correspondence to: Dr Smyth;} colin.smyth@tesco.net

Submitted 23 January 2001

Accepted 15 May 2001

Submitted 19 January 2001

Accepted 27 March 2001

\section{An elderly lady with collapse}

\section{F U Huwez, U Umasankar, D Aggarwal}

\section{Answers on $p 111$.}

A 78 year old women was admitted to hospital with collapse and sudden onset left sided hemiplegia and a right sided ptosis. On admission she was

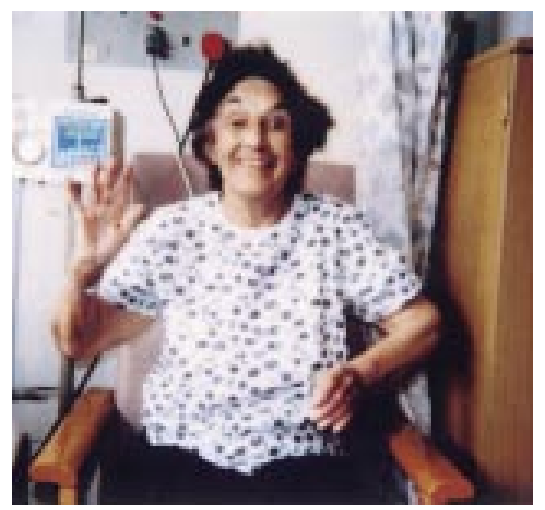

Figure 1 Patient with arms raised (reproduced with patient's permission). drowsy. She had a left hemiplegia and right ptosis. When the right upper eyelid was passively raised, there was a fixed outward deviation of the right eye. Both pupils were of equal size and reacting to light. No diplopia or sensory signs were noted at presentation.

\section{QUESTIONS}

(1) What are the findings in figs 1 and 2?

(2) What is the diagnosis?

Postgrad Med J 2002;78:105

\section{Authors' affiliations}

F U Huwez, U Umasankar, D Aggarwal, Stroke Unit (Lister Ward), Orsett Hospital,

Orsett, Grays, Essex RM16 3EU, UK

Correspondence to: Dr Umasankar; usankar68@hotmail.com

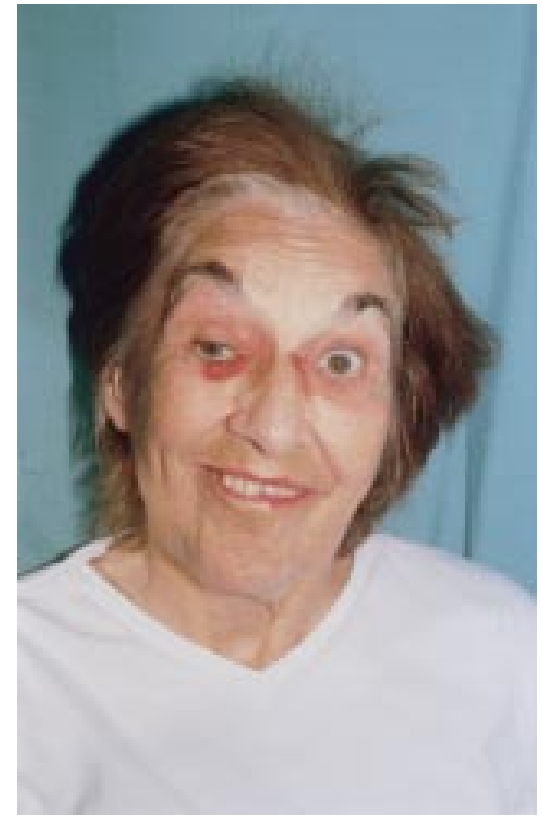

Figure 2 Patient's face showing clinical signs (reproduced with patient's permission). 